\title{
Risk Perception through Exemplarity: Hurricanes as Climate Change Examples and Counterexamples in Norwegian News Media
}

\author{
By Kyrre Kverndokk
}

\begin{abstract}
This article explores how hurricanes are used in news media to exemplify the consequences of climate change. This is done by a close reading of Norwegian newspaper articles on the hurricanes Katrina (2005), Sandy (2012), Harvey and Irma (both 2017). The geographical distance between the disaster areas and the media audience enables an exploration of how these weather events are made meaningful across long distances, as global concerns. The article shows how these hurricanes are textualized and turned into signs in nature that are pointing towards a climate-changed future, and how they work as modelling examples for imagining the possible disastrous state of such a future. It further argues that reasoning with hurricane examples is a certain kind of risk perception involving a temporal and spatial entwining of the future and the present, that represents a notion of cultural catastrophization by calling upon a fear of an uncontrollable disastrous future.

The uses of the hurricane example in news media imply an epistemological shift from probability to exemplarity. This shift provides an argumentative space for climate change skeptics to perform counterarguments that juggle between probability and exemplarity. The article explores how this is done, and how statistics and mentioning of other hurricanes are used to argue that hurricanes Sandy, Harvey and Irma were not extraordinary events in terms of intensity, and thus that they cannot possibly be fueled by climate change. The climate change skeptics' attempts to claim these hurricanes to be local and normal phenomena, independent of human action, may be regarded as attempts to de-catastrophize contemporary society.
\end{abstract}

Keywords: climate change, hurricanes, risk perception, exemplarity, risk society, semiotic worldview

Kverndokk, Kyrre: "Risk Perception through Exemplarity: Hurricanes as Climate Change Examples and Counterexamples in Norwegian News Media", Culture Unbound, Volume 11, issue 3-4, 2019: 306-329. Published by Linköping University Electronic Press: http://www.cultureunbound.ep.liu.se 


\section{Introduction}

In December 2012, the political leaders of the world were once again gathered to negotiate global climate politics and possible agreements. This time the UN Climate Change Conference was held in Doha, the capital of Qatar. A few days in advance of the meeting, the Norwegian daily Dagsavisen published a critical article on what to expect from the upcoming meeting, entitled "Closing their Eyes to the Climate Catastrophe". The introduction to the article is rather pessimistic: "The politicians of the world are unable to save the world. The emission of greenhouse gases continues to increase. It is therefore likely that there will be a catastrophic rise in temperature of up to five degrees" (Sandberg 2012). Then follows a short interview with the research director of CICERO, the Norwegian Center for International Climate Research, Knut H. Alfsen, describing the dystopic future prospects. "The world will be ugly, ugly, ugly, ugly with a temperature rise of five degrees. The last time it was four degrees warmer than now, Europe was a swampland. The world will not be possible to recognize", says Alfsen (Sandberg 2012). The article continues by refer-
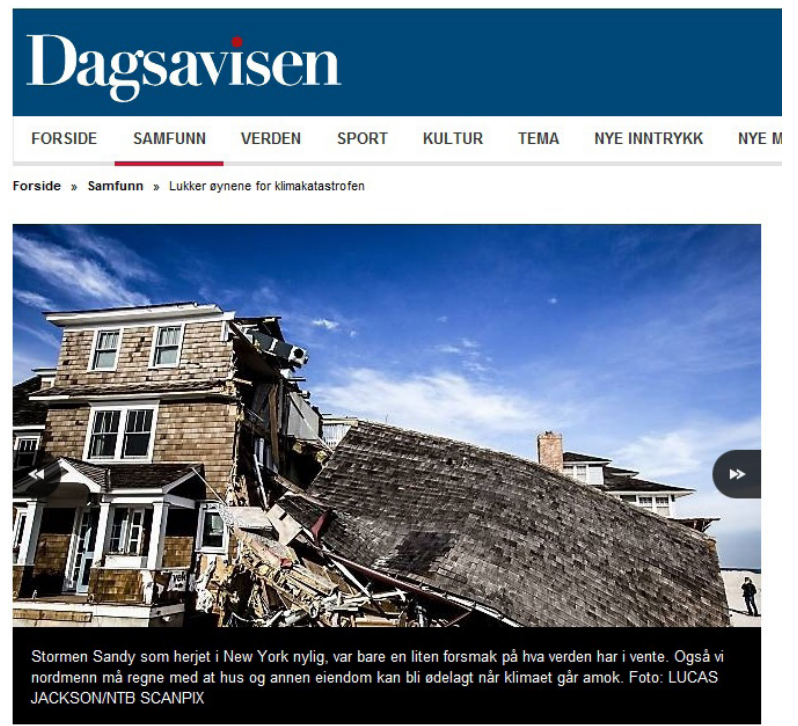

SAMFUNN

Lukker øynene for klimakatastrofen

Facsimilie from Dagsavisen 2012-12-03. ring to recent numbers from the Global Carbon Project documenting that if the contemporary emission rates of greenhouse gasses continued, it would lead to a five degree rise in temperature by the end of the century. This dramatic message is illustrated by a picture of a building that had collapsed, obviously due to severe wind. The caption reads: "The storm Sandy that devastated New York recently was only a small preview of what the world has in prospect. Even we Norwegians have to expect that houses and other property can be damaged when the climate runs amok" (Sandberg 2012).

The way this news article moves between Doha, Norway and New York City illustrates how popular climate change discourse is globalized. A weather incident in the USA might be used as an example to illustrate the climate-changed future in 
a totally different country, while political decisions made at a third location might have implications about whether or not the prediction will be turned into reality. Such rhetorical use of extreme weather events as examples of climate change effects are common in news media. In this article I will examine how extreme weather examples are used in news media to exemplify climate change. This will be done through an analysis of texts on hurricanes from Norwegian newspapers. I will discuss how the hurricanes are made "culturally meaningful for a particular audience" (Doyle 2011: 2, see also the introduction to this thematic section of Culture Unbound), in this case an audience on the other side of the Atlantic. The geographical distance between the disaster areas and the media audience enables an exploration of how these weather events are made meaningful across long distances, as global concerns.

Geographer Mike Hulme has suggested that climate might not merely be understood as a statistical description of weather over a period of time. While weather is in flux, climate has until recently been considered as a stable entity. Thus, climate, according to Hulme, might be understood:

\begin{abstract}
as an idea which mediates between the human experience of ephemeral weather and the cultural ways of living which are animated by this experience. The idea of climate introduces a sense of stability or normality into what otherwise would be too chaotic and disturbing an experience of unruly and unpredictable weather (Hulme 2017: 4).
\end{abstract}

The stable aspect of climate also includes a sense of predictability and security, according to Hulme. This is threatened when the climate changes, and there is no such thing as an ordinary climate anymore. In that regard, the climate involves affects, more or less dystopic imaginaries of the future, and also ethical concerns. The aim of this article is to explore some of the imaginaries, affects and ethics involved when specific weather events are being associated to climate change. This will be done by examining how "the hurricane", is textually produced and used as an example of climate change effects, and the article asks: What sort of understandings of the relationship between weather disasters, climate change and society are unveiled through uses of hurricanes as exemplifications of climate change?

\title{
Theoretical approaches and empirical basis
}

Examples might in general be regarded as rhetorical devices that establish connections between something specific and a general argument. They have the ability to relate a concrete case to an abstract statement (Eriksen et al. 2012: 9). There are two main kinds of example, those working as paradigmatic or modelling examples 
and those working as inductive or serial examples (Gelley 1995: 1-2). When arguing with examples, these kinds are often combined in more or less complex ways (Eriksen et al. 2012: 13). In order to work efficiently, both kinds of examples have to be based on common ground. They are rhetorical devices that are seemingly external to the text or communicative situation where they are used, or as literary scholar John Lyons puts it:

Example is a way of gesturing outside of the pure discourse of the speaker/writer toward support in a commonly accepted textual or referential world. As external to discourse, or as a unit of discourse separated from the unqualified enunciation of the speaker alone, example can be conceived as something that speaker and audience, writer and reader look toward as possible common ground. In this case example would be outside the 'inside' constituted by the discourse of direct assertion and would itself be a closed entity, which would present itself to be beheld by the public. (Lyons 1989: 28)

This claim draws on his study of the uses of examples in French and Italian renaissance literature. It may, however, also be said to characterize the example as a rhetorical figure in general, including the ways examples are used today in everyday communication, in politics, for educational reasons and by popular media (cf. Eriksen et al. 2012). In the newspaper article referred to in the introduction, Hurricane Sandy functioned as a "closed entity", gesturing towards "a commonly accepted $[\ldots]$ referential world". The example is not merely referring to the actual hurricane, it also gestures towards a climate-changed future. This gesture might only work rhetorically if the readers acknowledge the severe consequences of anthropogenic climate change. This exemplification would be regarded as meaningless or even a false claim, from the point of view of climate change skeptics.

Like all examples, the hurricanes have to be textualized in order to work rhetorically. They must be framed and presented as "closed entities" that are possible to transfer between different discourses and texts. The hurricanes must be "cut out" from the constant flow of weather and be entextualized as meaningful units. Folklorists Richard Bauman and Charles Briggs have defined entextualization as "the process of rendering discourse extractable, of making a stretch of linguistic production into a unit - a text - that can be lifted out of its interactional setting" (Bauman \& Briggs 1990: 73, their italics). The process of entextualization, does not only include the production of a text, it also includes processes of decontextualization and recontextualization. Bauman and Briggs emphasize that contexts are not fixed, predefined units but are rather co-produced as part of the entextualization process. In line with Bauman and Briggs, I regard the process of turning an 
extreme weather event into an example of climate change as a process of rendering an event extractable by making it into a textual unit. This process also requires carefully performed processes of (re)contextualization of the textualized weather event in order to work sufficiently as a rhetorical figure.

Following this analytical strategy, the article will examine Norwegian newspaper texts on four American hurricanes, Katrina (2005), Sandy (2012), Harvey and Irma (both 2017). These hurricanes are selected because they immediately turned into international media events and were associated to climate change. I have gone through the media coverage of these hurricanes by using the Norwegian media monitoring service Retriever. The names of the hurricanes and "climate"/"climate change" have been used as search queries. Retriever covers all Norwegian newspapers and media houses with one exception. In addition to news media, the database also covers some periodicals and press releases from larger organizations and think tanks. I have limited the corpus of texts to editorials, columns, news articles and letters to the editor published in paper-based or web-based news media, excluding feature articles and journalistic fields such as business, sports, culture and entertainment.

The search result has been used to identify some patterns in the usage of hurricanes as examples of climate change effects. Three main uses of the hurricane example have been identified and will be examined through close readings of a limited number of texts: The extreme weather event as a sign in nature previewing a climate-changed future, the weather related disaster as a demonstration of climate change risk and the hurricane as a counterexample used to argue against the notion of anthropogenic climate change.

\section{The Hurricane as a Rhetorical Figure in Popular Climate Change Discourse}

"The hurricane" has become a key symbol in popular climate change discourse, partly due to its dramatic character (see Kverndokk 2015: 219-235). While other natural phenomena associated with climate change, such as the melting of the Greenland ice sheet and the decrease in Arctic sea ice, are located in the far north wilderness, hurricanes bring the consequences of climate change into populous Western cities. They are, in science journalist Chris Mooney's words, "monstrous citysmashers" (Mooney 2007: 9). Hitting American cities, they have a potential for being broadcast live, reminding a global media audience how climate change fuels societal vulnerability.

The practice of naming them also facilitates hurricanes for being used as rhetorical devices. This practice goes back to the Second World War and was formalized in 1953. The hurricanes were given female names until 1979, and from that 
year the naming also included male names as every second one (Fitzpatrick 2006: 14-15). The US National Hurricane Center makes an alphabetic list of 21 hurricane names in advance of the hurricane seasons. The names may be re-used several times, but are taken out of circulation if the hurricane becomes a media celebrity. The name Katrina has, for instance, been used six times, but not after 2005. The naming transforms a hurricane from being just another occasion of more or less disastrous wind and heavy rain to unique event. They become clearly defined, textual objects, which makes them easy to refer to as singular events.

Hurricanes have been associated with climate change at least since the beginning of the 1990s, but it was Hurricane Katrina that turned them into a main topic in transnational popular climate change discourse (Boykoff 2011: 136, Mooney 2007: 150). Already on the day of the landfall, 29 August 2005, Time Magazine posed the question "Is Global Warming Fueling Katrina?" (Kluger 2005). The environmentalist Ross Gelbspan followed up two days later in The New York Times by claiming: "The hurricane that struck Louisiana and Mississippi on Monday was nicknamed Katrina by the National Weather Service. Its real name is global warming" (Gelbspan 2005).

The dramaturgy of the disaster partly explains why this particular hurricane was framed by popular media and environmentalists as a climate change event. In the essay "Global Storm Warning," the environmentalist Mark Hertsgaard explains it in this way:

It's hard to imagine a more clear-cut wake-up call than Hurricane Katrina; environmentally speaking, it was nearly the perfect storm. In a single catastrophic event, it brought together the most urgent environmental problem of our time - global warming - with the most telling but least acknowledged environmental truth: When the bill for our collective behavior comes due, it is invariably the nonwhite, nonaffluent members of society who pay a disproportionate share. And who said Mother Nature has no sense of irony? Katrina (and then Rita) struck at a major production site for America's oil and natural gas - the two carbon-based fuels that, along with coal, help drive global warming. (Hertsgaard 2006: 17)

Hurricane Katrina was simply the perfect extreme weather event to be used as an example of climate change effects. According to Hertsgaard, it almost made itself. Yet, what Hertsgaard actually does in this quote is to pinpoint some major aspects of how and why this hurricane could rhetorically be framed as an example; the location of the disaster, its victims and the national and international political context. By describing the hurricane as a scene exposing the relationship between 
social vulnerability and climate change, he turns the disaster into a narrative with the people in New Orleans as victims, the oil industry and "our collective behavior" as villains, and nature as the driving force of the story. It is a narrative in need of heroic action - not merely as relief work - but rather as severe reorientation of national and global environmental politics. The quote may almost be regarded as a recipe for how to use Hurricane Katrina as a rhetorical figure in climate change discourse.

\section{Hurricane Katrina as an Object Lesson}

The framing of Hurricane Katrine as a climate change event also dominated the Norwegian media coverage of the disaster. Already on 31 August, less than two days after the hurricane hit New Orleans, the tabloid Dagbladet, the third largest newspaper in Norway 2005, published an editorial entitled "Even more Extreme Weather". This is a larger excerpt:

Katrina has caused severe damage in New Orleans and put larger parts of the city under water. [...]

Katrina's ravages provide an object lesson in what happens when the weather becomes extreme. The experts are careful not to directly link this particular hurricane to global warming. This year's hurricane season can become one of the worst, yet it may be a part of a 50 to 60 -year weather cycle. But, however, only various supporters of the oil industry, found among politicians and scientists, doubt that climate gas emissions are warming the planet, causing climate change and extreme weather. Hurricanes are not the only form of extreme weather.

Warm, still weather that causes drought can be even more destructive.

Extreme weather in our own country manifests itself as summer storms in the Western regions [of Norway]. Or we see it as bushes and small trees growing in the mountain plateaus where we are used to alpine vegetation. The Minister of Environment, Knut Arild Hareide, promises that as long as his government is allowed to stay in power, the loss of Norwegian nature as we know it will be halted during the next Parliamentary term. This is an impressive promise that Hareide will be unable to keep when nature strikes back.

Katrina has struck New Orleans hard. On a local level, human activity has contributed to making the city more vulnerable when storms hit. Combined with an influx of water in the Gulf of Mexico, the construction of dams and development of real estate, oil extraction, and other 
industries have made the water levels in the Mississippi Delta rise by almost a meter.

The time came long ago to stop listening to the oil industry's claqueurs who deny the now well-documented connections between emissions and future extreme weather, whether they are politicians or scientists. The goals of the Kyoto agreement are far from adequate in order to stop the increase in climate gas emissions. Extreme weather is a reminder of what awaits us if we don't do much, much more. Now. (Dagbladet 2005: 2)

This editorial textualizes the disaster as a specific rhetorical figure by claiming that "Katrina's ravages provide an object lesson in what happens when weather becomes extreme". The term "object lesson" refers to the pedagogical ideas of Johan Heinrich Pestalozzi (1746-1827). He emphasized the importance of using physical objects or visualizations as pedagogical devices. By terming the disaster an object lesson, Dagbladet launches the disaster as a pedagogical example, demonstrating what a climate-changed future will be like.

In order to fully work as such an example there must be some sort of causal connection between climate change and the hurricane. However, this is difficult to claim from a scientific point of view. Meteorological research may calculate the risk for stronger and more frequent hurricanes due to increased ocean temperatures, but such research cannot directly prove that single events are caused by climate change (cf. Field et al. 2012: 127). Hence, in line with climate research, the editorial is careful not to draw a direct causal link between climate change and the hurricane. Instead of going into a discussion on likelihood and probability, the editorial turns to an argumentation based on examples. The term that enables this shift is "extreme weather".

This term emerged in the USA in the 1980s. The new genre of weathertainment developed by TV-channels such as The Weather Channel used it to describe spectacular weather events such as hurricanes (Nielsen 2014: 22-23). "Extreme weather" appeared for the first time in Norwegian press in 1994, as a term for describing a heavy storm (Halden Arbeiderblad 1994). It was defined and given formal content a year later by The Norwegian Meteorological Institute. The term was then launched as a weather category to be used in a new forecasting procedure notifying weather events that could cause severe societal damages. "Extreme weather" was then not defined by meteorological criteria, but by the societal and economic risks. It was a formal preparedness category that included all sorts of weather events that could cause severe societal damage, such as storms, storm surges, heavy rainfalls and other weather conditions causing possible floods, avalanches and landslides (Nilsen \& Vollset 2016: 389-395). Thus, the category "extreme 
weather" brings different weather phenomena together, seemingly transforming them into phenomena of the same kind. This was also the intention by coining it as a preparedness category. At the same time, this way of bringing together different types of weather also makes "extreme weather" an efficient rhetorical figure, far beyond a preparedness system.

The same year as "extreme weather" was coined as a preparedness category, it also appeared in Norwegian media as a term associated with climate change. According to STS-scholar Marianne Ryghaug, it eventually became a dominant trope in Norwegian climate journalism (Ryghaug 2006: 204-205). This seems to have happened in the mid-2000s, partly due to the storm Gudrun that caused severe damage in Southern Scandinavia in January 2005 and Hurricane Katrina in August the same year (Nasjonalbiblioteket). Hence, the lay and media use of the term "extreme weather" has at least three connotations. It may at the same time connote the causes (climate change), the unfolding (spectacle) and the consequences (as a preparedness category) of a weather event. This adds a rhetorical plasticity to the term.

This plasticity is visible in how the term is used in the editorial from Dagbladet. Hurricane Katrina is first exposed as a spectacle, as "Katrina's ravages". It is this spectacle that is named an object lesson. In the following sentences, however, it is made clear that it is not the storm as such that is of interest, but rather the trinity of a weather spectacle, its climatic causes and its societal consequences, summed up in the term "extreme weather". By claiming that "[h] urricanes are not the only form of extreme weather", the article explicitly unites different kinds of weather phenomena appearing at different locations around the world; Hurricane Katrina, drought, summer storms in Norway and "bushes and small trees grow in the mountain plateaus where we are used to alpine vegetation". These phenomena are brought together as indicators of global warming. They seemingly work as a list of observable evidences of climate change, which could almost be mistaken for a list of statistic data. Yet, in this case they primarily work as a list of examples of climate change effects. These examples serve two functions. They are contemporary exemplifications of climate change effects and they are "reminder[s] of what awaits us if we don't do much, much more. Now." In the latter regard, the listed examples work as communicative signs pointing towards a climate-changed future. Hence, regarded as signs they bring a message from nature to the humankind about the future. They are a list of forewarnings of a larger, climate disaster that will emerge "when nature strikes back". This argumentative pattern has striking similarities with an older way of reasoning - omen reading. 


\section{Reading Signs in Nature}

The art of reading omens was both an intellectual and a vernacular practice in early modern Europe. In the early modern semiotic worldview, nature was understood as a divine text. It was considered possible to read God's plan out of nature, by using the Bible as the code for interpreting the signs (cf. Frye 1982, Gilje \& Rasmussen 2002: 203-233). Rare phenomena and dramatic events such as weather events and disasters were read in light of eschatological verses of the Scripture and were regarded as prefigurations of forthcoming major disasters, most often Judgment Day. The eschatological interpretations of such signs were often also authorized by listing a number of ominous signs occurring more or less at the same time. These signs could in principle occur at totally different locations around the world. The Lisbon earthquake of 1755 was, for instance, interpreted around Europe as an omen predicting the emergence of the Last Days. The earthquake was not only seen in relationship to other earthquakes around the world; the eschatological interpretation was also supported by listing other peculiar occurrences that were considered as typical omens, such as floods in France, a blood-red rainfall in Switzerland, a comet observation in Sweden, and five moons observed in the sky over Poland. Each one of these incidents was perceived as remarkable. Linked together they formed an ominous semiotic pattern, predicting the end of the world (Kverndokk 2019).

The early modern and late modern knowledge regimes are fundamentally incomparable. Yet, despite the fundamental differences between the way the editorial in Dagbladet argues and the early modern reading of omens, there are three striking similarities. First, the contemporary extreme weather events are also read as signs. Both the early modern and late modern natural occurrences are constituting semiotic patterns pointing towards a disastrous future, though leaning on quite different authorities. The early modern interpretations of signs were authorized by the Bible, while those in Dagbladet are authorized by references to science. Second, none of these signs, neither the early modern ones nor the ones listed in the editorial, appeared without reason. Each one of the early modern disasters were regarded to be caused by sin that triggered the wrath of God locally. At the same time, a semiotic inter-spatial pattern of such extraordinary events indicated a universal reason; human beings as sinners, with their inherited original $\sin$. The editorial from Dagbladet also explains the causes for "Katrina's ravages" to be two-leveled. The direct cause of the disaster is explained to be local vulnerability due to "the construction of dams and development of real estate, oil extraction, and other industries [that] have made the water levels in the Mississippi Delta rise by almost a meter." While the final cause is explained as being "that climate gas emissions are warming the planet, causing climate change and extreme weather". And third, the forthcoming disastrous futures, the early modern apocalypse and 
the disastrous climate-changed future, are presented as the consequences that will occur if not the destructive (sinful) human behavior does not end very soon. In both cases the specific disasters or natural incidents are at the same time understood as self-blamed incidents and warnings that call for action. In that regard, the natural incidents in both omen readings and in the text from Dagbladet imply a moral aspect.

The intricate play between the disastrous events as punishments and as warnings are similar in early modern readings of omens and the editorial from 2005. Historian Gerrit Jasper Schenk has argued that what he terms "a secular theology of punishment" is present in contemporary climate change discourse (Schenk 2009: 12). He draws a line from the notion of divine punishment in early modern theology to the emphasis on the moral connection between human action and natural disasters in contemporary climate change discourse. Historian David Larsson Heidenblad has argued in similar terms. He claims that the early modern notion of divine punishment and the moral figuration of poplar climate change discourse both draw on so-called "moral causality" (Heidenblad 2012). In late modern popular texts on climate change, nature is no longer a tool used by God to punish sinners. Nature is instead given agency as an autonomous force. The editorial from Dagbladet is quite typical in that regard. Nature is presented as an authority punishing or "striking back", while it at the same time also is warning humans not to bring it out of balance. Such potential imbalance between nature and society is a frequently returning motif in popular climate change discourse. This motif is unveiling a notion of nature as a gatekeeper of the limits for human exploitations of the environment (cf. Holm 2012: 24-26). Throughout the modern era "nature" has been ascribed a self-authorized indisputable moral authority, according to historians of science, Lorraine Daston and Fernando Vidal (cf. Daston \& Vidal 2004: 5-6). This moral aspect of nature serves as the basis for its gatekeeping position in texts such as the editorial from Dagbladet. Hence, as an object lesson, Hurricane Katrina is connecting the future to the present through moral causality, by demonstrating the obligation of immediate action to avoid a climate-changed, disastrous future. This way or reasoning must be regarded as a kind of risk perception, but not primarily in terms of calculations of uncertainty and probability. This is rather a way of reasoning that evokes a general sense of danger connected to contemporary carbon emissions, by pointing to a number of warnings. 


\section{Exemplifying Cultural Catastrophization}

The textualizing of Hurricane Katrina as an object lesson in climate change, underscores how a local disaster also is perceived as a global concern, and how the lesson learned even might be relevant for a Norwegian audience. This way of connecting disasters to everyday life of audiences far away is common in popular climate change discourse. Another example is the newspaper article from Dagsavisen which I presented in the introduction. By claiming that Hurricane Sandy was "a small preview of what the world has in prospect", this article makes the hurricane relevant for audiences on the other side of the globe, while it at the same time makes it relevant for international climate politics. These connections are established through reading the hurricane as a sign in nature, pointing towards a disastrous future. In that regard, the hurricane example establishes both trans-spatial and trans-temporal connections.

The headline of the article is, as mentioned: "Closing their Eyes to the Climate Catastrophe" (Sandberg 2012). The term "the climate catastrophe" is commonly used in several European languages. It is most often written in singular and in the definite form. In that way it includes all possible disastrous effects of climate change. In other words, it incorporates quite different natural processes and events taking place at different times and places around the world and turns them into aspects of one all-embracing forthcoming disaster. The term is in that regard apocalyptic. The apocalyptic figuration of a climate-changed future has been widely examined (e.g. Anshelm \& Hultman 2015, Cochet 2015, Hörnfeldt 2018, Hulme 2008: 10-13, Johns-Putra 2016, Lilly 2016, Northcott 2015). The climate apocalypse is, however, often referred to by scholars in rather simplified terms, as a metaphor for an emerging societal collapse (Skrimshire 2014: 237-239). The apocalyptic framing of a climate-changed future is of course metaphoric, in the sense that it is a secular imaginary and is thus not describing a transition from an earthly to a heavenly world. But it is more than just a metaphor. It is also a temporal structure organizing the relationship between the present and the end. Literary scholar Frank Kermode terms this temporal structure kairos, which is one of two Greek words for describing time. The word chronos means "passing time", while Kermode describes kairos as "a point of time filled with significance, charged with a meaning derived from its relation to the end" (Kermode 1967: 47). The apocalypse is in other terms as much about the significance of the present as it is about the future. The usage of hurricanes Katrina and Sandy as examples in the editorial from Dagbladet and the article from Dagsavisen follows this temporal structure. In both cases they exemplify how present-day events are "charged with a meaning derived from [their] relation to the end".

The temporal and spatial entwining of the future and the present in these texts also implies an entwining of risk and fear for actual, emerging, potential and pre- 
dicted natural disasters around the globe. It can be argued that this kind of rhetoric reflects what sociologist Ulrich Beck has termed the risk society. According to Beck, the risk society is characterized by hazards and risks that are uncalculatable, uncontrollable, trans-local and even global, such as climate change effects. It might also be argued that the practice of reading hurricanes as signs prefiguring a disastrous future is catastrophizing everyday life, in the sense that it calls upon a fear for an uncontrollable disastrous future, and likewise encourages a safety-desiring state of emergency (cf. Ophir 2010). Such a cultural catastrophization is not necessarily demotivating, it might just as well motivate for political action. Beck argues that the notion of globalized and imminent risks might generate a globalized commonality of anxiety, from which a "solidarity from anxiety arises and becomes a political force" (Beck 1992: 49, Beck's italic). The way the hurricanes are used as examples of climate change effects in the two texts close read so far, might be regarded as a rhetorical strategy to call upon such a globalized solidarity by appealing to a sense of anxiety of the uncontrollable climate-changed future.

\section{Exemplary Climate-Changed Spectacle}

The science journalist Bjørn Vassnes publishes a weekly column in the leftist newspaper Klassekampen, commenting on current scientific debates or discoveries. On 7 September 2005 the column was dedicated to Hurricane Katrina, climate change and risk perception. The article is entitled "We All Live in New Orleans", emphasizing that the hurricane also has relevance for Norwegian newspaper readers. This article is in contrast to the two texts examined so far, not reading the hurricane as a sign in nature. It is instead placing the disastrous scenes from New Orleans at the center of the argumentation.

Vassnes opens the article by claiming that " $[n]$ o matter how urban we think we are, we will never get away from nature", before he demonstratively turns the disaster in New Orleans into a rhetorical figure:

What happened in New Orleans is more than a natural disaster, it is a metaphorical event of historical dimensions, which can hopefully lead a way for a new realism both in the USA and around the globe. Located below sea level, with too fragile protections against the forces of nature, the drowned city has become a symbol of the whole world, and for the contemporary USA in particular. The destiny of the city is a metaphor for what may hit all of us if we continue our mindless denial of nature. We have for a long time pushed environmental problems and an accelerating greenhouse effect under the carpet, constructed higher and higher levees against reality, and not realized that we have just made 
ourselves even more vulnerable when the flood eventually appears.

(Vassnes 2005)

A metaphor is in general a rhetorical device that implies a resemblance between what it denotes and what it is supposed to illustrate. By doing so, the metaphor has the capability to mediate between different phenomena, events, utterances and texts. It establishes connections between different domains of meaning, and it also opens for entanglements of concepts, descriptions, associations and imaginaries in between these domains (Turner 1974: 25-30, Lakoff \& Johnson 1980). Thus, the use of terms such as "metaphor" and "symbol" is a way of textualizing the hurricane and works as a linguistic and narrative gate opener.

What Vassnes calls "[t]he destiny of the city" is not just the simple fact that the hurricane caused severe damages in New Orleans. It also brings associations to the stories that had been displayed to a transnational audience through ten days of intensive news coverage. The news from the disaster area was first and foremost portraying chaos and the absence of the authorities and was structured through a limited number of narrative motifs, such as looting and snipers shooting at helicopters (cf. Dynes \& Rodríguez 2007: 24-25). The football stadium Superdome was used as a temporary shelter, even though it had no electric power, no functioning air condition, and terrible sanitary conditions. As the days went along, more than 30000 people gathered there, and descriptions of the terrible conditions went around the world, including rumors about murders and rapes. Norwegian media used metaphors such as a "war zone" and analogies to specific war zones like Bagdad, Somalia and Afghanistan to illustrate the situation. One profiled news commentator even compared the conditions in the Superdome with the Thunderdome, the gladiatorial arena in the post-apocalyptic Mad Max movies from the 1980s (Kverndokk 2015: 197-210). Thus, by claiming that "[w]hat happened in New Orleans [...] is a metaphorical event of historical dimensions", Vassnes does more than just refer to the despair, he also opens for associations to chaos, violence, lawlessness, rape, murder and war zone-like conditions. It is these things that "may hit all of us, if we continue our mindless denial of nature".

As a rhetorical device, a metaphor merely portrays likeness between two objects, it does not claim any necessary connection between them. In this text, however, Vassnes claims more than just coincidental similarity between "[w]hat happened in New Orleans" and a climate-changed future. Claiming that " $t]$ he destiny of the city is a metaphor for what may hit all of us if we continue our mindless denial of nature" he also implies referentiality. Thus, Hurricane Katrina is in this case not just a metaphor. The sentence rather presents the hurricane as an exemplification of how a disastrous climate-changed future might look like.

The hurricane works as such an exemplification in two senses. First, it exem- 
plifies how climate change might unfold as post-civilized scenes. Vassnes returns to the analogy between the spectacle from New Orleans and a devastating climate-changed future in the concluding paragraph of the article:

[W]e all live in New Orleans: No matter how modern and urban we think we are, we will never get away from nature, whether it is as flood, drought or epidemics. And the more we forget this, the stronger will the shock be when nature breaks through the levees. (Vassnes 2005)

"[W]e all live in New Orleans", does not primarily express empathy with the victims. It rather emphasizes the possibilities for similar scenes as those in New Orleans to unfold at other locations in the future. In that regard, Hurricane Katrina is used as an instructive narrative, a warning to take example from.

Second, the hurricane also works as a serial example that illustrates how climate change might cause natural disasters: "Katrina is exactly what many climate scientists have predicted: that storms and hurricanes will increase in intensity as the ocean temperature rises. What gave Katrina its power was the extremely high temperatures in the Gulf of Mexico, around 30 degrees" (Vassnes 2005). The pedagogical quality of this example is underscored by using the adverb "exactly". This adverb might also imply a direct causal link between climate change and the hurricane. Yet, as a science journalist, he is aware of the scientific uncertainty and multicausality that makes such a claim difficult. His intention is, however, not to discuss uncertainty, but risk.

This risk has both quantitative and qualitative dimensions. Vassnes claims that " $[w]$ e can no longer afford to gamble that the extreme weather that almost the entire globe is experiencing (it is just as much in many other places) is a random variation". Hence, he is referring to risk in terms of frequency. While when he claims that the disaster in New Orleans "a metaphorical event of historic dimensions" he also includes the scenes from the disaster area in his notion of risk.

\section{Risk and Ethics}

By focusing on increased risk rather than uncertainty, Vassnes turns the attention away from meteorological processes towards ethical concerns. He uses two examples from quite different societal fields to illustrate his point; one medical example about smoking and one legal example about drinking and driving:

One can never know exactly what will trigger cancer. A deadly mutation can emerge even if one does not smoke. If a heavy smoker dies of lung cancer, it is therefore possible to claim that it has not been proved 
that it was the smoking that caused the disease. But we still have enough sense to try to limit the smoking, because we know that smoking causes higher risk.

One who has run over a person under the influence of alcohol will probably also claim that it is not possible to prove that it was the alcohol that made him do the wrong maneuver. In theory, that might have happened anyway. But he would probably not get any understanding for this view in court, because he should know that drinking increases the risk of traffic accidents. (Vassnes 2005)

These examples involve commonly accepted risks and are easy to agree on. Vassnes uses them as parallels to climate change risk. They are not just comparable in terms of frequency and probability. They are also demonstrating an equal lack of judgement. The medical example is simply presented as a question of "hav[ing] enough sense to try to limit the smoking". While the legal example is rhetorically more powerful by also including risks of injuring or even killing others. Vassnes emphasizes the ethical parallel by linking the drinking and driving example directly to the situation in the USA:

But the elected President of the USA will nevertheless continue to 'drink and drive', with the rest of the world as involuntary passengers or victims. He will not do anything drastic regarding the greenhouse [gas] emissions. And until now he has been supported by the population: Nobody would get elected for President if they promised to triple the gasoline prices. (Vassnes 2005)

By using the metaphor "drink and drive" Vassnes makes the parallel to the lack of climate change politics by the Bush administration explicit, in terms of poor risk perception, lack of judgment and moral responsibility. He is underscoring the ethical aspect by referring to Germany's Minister of the Environment, Jürgen Trittin, from the Green Party, who a few days earlier had stated that: "the USA probably must have itself to blame for this natural disaster, because they are leading the way in the gigantic experiment with life, health, climate and nature, which is the ever-increasing greenhouse gas emissions" (Vassnes 2005). Thus, the moral responsibility concerns both the risk for future disasters and the guilt for this specific disaster.

The paring of risk perception and a notion of moral responsibility enables Vassnes to use Hurricane Katrina not only to criticize the Bush administration, but also to point towards everyday practices around the world, including Norway. People are in general morally responsible for future disasters by not being willing 
to change their lifestyles, he concludes.

There are several similarities between the way the hurricane is framed and used as an example this column, the editorial from Dagbladet from 2005 and the news article from Dagsavisen from 2012. The hurricane is in all these cases used in a pathos-driven and affective argumentation, making climate change a fundamentally ethical concern. All the texts stress the ethical aspect of nature, by describing nature as a righteous moral force, correcting and punishing humans when interfering the balance between society and nature. Hence, they all include a complex temporal structure, by entwining future and present-day disaster. Even though Vassnes' does not read the hurricane as a sign in nature, his argument still involves more than just increased likelihood and frequency of disasters. In his text, the scenes from New Orleans also work as reminders of the thin line between civilization and chaos, as such the disaster works as a scary, modeling example for imagining climate related disasters that might hit anywhere at any time in the future. In that regard this column also reflects a catastrophized notion of emergency in the risk society.

\section{Undermining the Exemplarity of the Hurricane}

I will now move to how the hurricane is rhetorically used to argue against the likeliness of anthropogenic climate change. There has been published a number of studies the last decade on climate change skepticism. They cover a specter of related phenomena from repression of the problem in everyday life to organized, politically and economically motivated skepticism (e.g. Dunlap \& McCright 2011, Nordgaard 2011, Schlosser 2018). This research has also shown how active skeptics often emphasize the uncertainty of climate change research and some actors are even manufacturing data to underscore the uncertainty (Dunlap \& McCright 2010). My contribution to this field of research will be on the rhetoric of skepticism.

I have shown that there is an observable epistemological shift from probability to exemplarily in the editorial "Even more Extreme Weather" (Dagbladet 2005). I have further argued that Vassnes' notion of risk perception is not limited to frequency and probability. His framing of the hurricane as an event to take example from has obvious similarities with Mark Hertsgaard's claim that the hurricane was "nearly the perfect storm" (Hertsgaard 2006: 17). Thus, Vassnes' argument is also involving a similar epistemological shift from probability to exemplarity. This shift opens an epistemological gap between probability and exemplarity that enables climate change skeptics to perform counterarguments by juggling between probability and exemplarity.

Climate change skeptics wrote letters to the editors of local and national news- 
papers in the aftermath of both Hurricane Sandy in 2012 and hurricanes Harvey and Irma in 2017. One main argument in these letters was that the hurricanes were not extraordinary by strength. After Hurricane Sandy, a reader of the local newspaper Telen, published in the town Notodden, wrote:

The editor's leading article in Telen on 30 October appears to me to be pure scaremongering. $\mathrm{He}$, and larger parts of the Norwegian media, had pulled 'the climate card' even before Hurricane Sandy hit land. Excessive claims have been made, such as: 'The biggest hurricane of all time.' 'Never before in history have we seen a hurricane of such a large size,' 'The monster Hurricane Sandy', 'We can expect more extreme weather in the future, etc. etc ... and everything is due to man-made climate change!

What the media 'forget' to mention, in their attempts to be politically correct according to the government's climate policy, is that the time frame of 'history', which is so often talked about, really is a microscopic part of human history. How reliable are the claims when it turns out that the phrase 'the most powerful of all time' really just concerns the last 100 years of the history of the Earth? They also 'forget' to mention that there actually have been several more powerful hurricanes during the last century. Ca. 8000 people died in the Galveston Hurricane in the year 1900, and between 600 and 800 people died in the Atlantic Gulf Hurricane in 1919. These [hurricanes] were surely not a result of manmade climate change? (Rønning 2012)

While a reader of the national newspaper Aftenposten commented the uses of hurricanes Harvey and Irma (2017) as climate change examples in this way: "On a list of hurricanes by strength, Irma is listed at seventh place and Harvey at eighth - the latter [the eighth place] shared with hurricanes Georgia (1898) and Hazel (1954). This will be difficult to explain by $\mathrm{CO}_{2}$ and rise in temperature" (Eklund 2017). It is, however, not given any information about the survey the list is based on, what period of time it covers and whether or not it is restricted to Atlantic hurricanes.

In a column in the right-wing online news magazine Reset in October 2017, Professor emeritus of chemistry Ole Henrik Ellestad stated that:

For nearly 30 years, the IPCC and the Norwegian public have worked systematically to present increased extreme weather [as something] caused by man-made climate change. [....] But Norwegian extreme weather statistics after 1994 show no increased tendencies [...]. The IPCC-report on extreme weather from 2012 concluded that in a global 
perspective, extreme weather will be dominated by natural variations for the next 20-30 years. No increased tendencies concerning hurricanes, tornadoes, droughts, or other impacts were confirmed in the 2013 report. (Ellestad 2017)

These three articles demonstrate how the hurricane examples are excessive, and to some extent uncontrollable (cf. Lyons 1989: 34). As a rhetorical device, an example is based on an assumption that it represents a common ground, as piece of unquestionable reality (Lyons 1989: 28). Yet, an example might also be turned the other way around and be used to dispute such common ground. This is done in these three texts. They undermine the exemplarity of the hurricanes by referring to a list of other examples (Rønningen 2012), a statistic-based list of the hurricane intensity (Eklund 2017) and weather statistics (Ellestad 2017). The listed examples and the statistics work as seemingly neutral facts, as measurable and historical truth, demonstrating that the hurricanes Sandy, Harvey and Irma were not extraordinary. By doing so, these articles try to undermine the basis for claiming that these hurricanes were caused by climate change. At the same time, they also produce a shared counterexample. Their opponents' way of arguing is turned into an example of tendentious and unreliable reasoning, performed with the purpose of fooling the public opinion. The addressees of the critique are the core participants in the public climate debate. The reader of Aftenposten criticizes climate change researchers, the letter from Telen claims that Norwegian media are presenting "pure scaremongering", while, the column in Reset attacks politicians, the Norwegian public and "those supporting IPCC" in general terms.

Several scholars have argued that climate change skepticism is often related to an embracement of industrial modernity (e.g. Anshelm \& Hultman 2015: 100119, Dunlap \& McCright 2011, Schlosser 2018). This might also be the case with these texts, at least they repudiate any attempt to understand the present as a crisis of modernity. Hurricanes Sandy and Harvey do not represent anything more than themselves and do not have any significance, other than causing local disasters. These hurricanes are even claimed to be quite ordinary events, as events that simply happen from time to time. They have no relevance for understanding the future of the globe or the humanity. Paradoxically, by claiming the ordinariness of these storms, such reasoning also attempts to de-catastrophize contemporary society, in the sense that it rejects letting contemporary weather events generate risk and fear for potential and future disasters. 


\section{Conclusion: Risk Perception through Exemplarity}

Anthropologist Mary Douglas and political scientist Aaron Wildavsky open their book Risk and Culture in this way:

Can we know the risks we face, now or in the future? No, we cannot; but yes, we must act as if we do. Some dangers are unknown; others are known $[\ldots]$. Hence, no one can calculate precisely the total risk to be faced. How, then, do people decide which risks to take and which to ignore? On what basis are certain dangers guarded against and others relegated to secondary status? (Douglas \& Wildavsky 1983: 1)

With these words they raise some fundamental questions about risk and demonstrate how risk perception is a cultural phenomenon. This also counts for risk perception concerning climate change. The risks connected to climate change are just to some degree possible to model and calculate. The art of calculating the effects of climate change on the natural environment is complex and multivariate, and so are the uncertainties of these calculations. It is even more difficult to predict the societal effects of a warmer climate. How society develops in a climate changed future depends on far more than Earth system changes. It also depends heavily on factors that are impossible to scientifically model or calculate numerically, such as culture, religion and politics (cf. Hulme 2011: 165-166). Hence, dealing with the risk of a future climate-changed world requires more than knowledge offered by the hard sciences. To use the words of Douglas and Wildavsky, not even scientists "can calculate precisely the total risk to be faced." While it is difficult for scientists, it seems like an almost impossible task for non-scientists.

The use of the hurricane as a climate change example in the media must be regarded as risk perception in the interface between the dissemination of science and vernacular reasoning. The combination of the severity of climate change and the many factors of uncertainty concerning a climate-change future facilitates an epistemological shift from probability to exemplarity. To use hurricanes as contemporary exposures of a disastrous future might be helpful for imagining and describing some possible consequences of climate change. It is a way of producing an experienced basis for imagining and predicting the unpredictable future, where both weather patterns and the climate will change fundamentally.

The reading of weather events as signs in nature pointing towards a climate-changed future might also indicate that the Western world never really left a semiotic worldview. Natural phenomena are still read as signs, even though the signs are no longer perceived as divine, just signs of the emerging imbalance between nature and culture. This kind of reasoning implies a trans-temporal and trans-spatial notion of disasters, risk and responsibility. It represents a wider ten- 
dency of cultural catastrophizion of contemporary society by spinning a web of contemporary and future disasters, and through that web invoking an existential anxiety for an emerging disastrous world (cf. Kverndokk 2015: 264-269). I have argued that the temporal structure of such example-driven rhetoric can be termed kairos, emphasizing the present as "a point in time filled with significance, charged with a meaning derived from its relation to the end" (Kermode 1967: 47). The future is moved into the present, and the long-term consequences of climate change is condensed into a moment of either action or ignorance. Thus, there is an eschatological undertone in this way or arguing, transforming the present moment to both a "time of judgement" and a "time of repentance" (Northcott 2015: 108, cf. Smith 1969).

I have also shown how reasoning with hurricane examples enables the production of counterexamples to be used by climate change skeptics. These counterexamples are devices for dividing between natural and environmental risks, and nature and morals. Hence, they also work as devices for de-connecting the hurricanes from any trans-local and trans-temporal catastrophic pattern. This counter-reasoning is based on a plain chronological temporal structure, where the present is nothing more than a just a brief moment in the history of progress and development. Such de-catastrophization of society constitutes a basis for arguing that we might as well go on living our lives as usual, being fundamentally unconcerned about the future of the world. This is the flipped side of climate change risk perception through exemplarity.

Kyrre Kverndokk is Professor of Cultural Studies, at the Department of Archaeology, History, Cultural Studies and Religion, University of Bergen. He has published on Second World War memory, the history of folklore studies in Norway and the cultural history of natural disasters. He is currently leading the research project "The Future is Now: Temporality and Exemplarity in Climate Change Discourses”. E-mail: kyrre.kverndokk@uib.no

\section{Acknowledgements}

I acknowledge support from the Research Council of Norway to The Future is Now: Temporality and Exemplarity in Climate Change Discourses, project number 268094. I would like to thank Anne Eriksen, John Ødemark, Lone Ree Milkær, Camilla Asplund Ingemark, Henrik H. Svensen, Marit Ruge Bjærke, Diane Goldstein, and Hall Bjørnstad for stimulating discussions about climate change exemplarity. 


\section{Culture Unbound}

Journal of Current Cultural Research

\section{Notes}

${ }^{1}$ All the translations from Norwegian are done by the author, except the editorial "Even more Extreme Weather!", translated by Heidi Støa and the author.

${ }^{2}$ The newspaper Dagens Naringsliv terminated the cooperation with Retriever in September 2017.

${ }^{3}$ Atlantic hurricanes thus have a far higher potential of being turned into transnational media events than hurricanes, cyclones and typhons that hit the Indian subcontinent, Pacific states, Central America and Caribbean islands (cf. Kverndokk 2015: 10-12).

${ }^{4}$ The letters Q, U, X, Y and Z are not used. The Greek alphabet is used as a supplement if the number of hurricanes during a season exceeds 21 .

${ }^{5}$ Carl Lindahl and others has shown that these rumors were just rumors, no killing or rapes has been reported (see for instance Lindahl 2012). This is however not significant for my analysis.

${ }^{6}$ I prefer the term climate change skepticism rather than denial, due to the problematic connotations to Holocaust discourse by the use of the noun denial.

\section{References}

Anshelm, Jonas \& Martin Hultman (2015): Discourses of Global Climate Change: Apocalyptic Framing and Political Antagonism. Abingdon, UK: Routledge.

Bauman, Richard and Charles L. Briggs (1990): "Poetics and Performances as Critical Perspectives on Language and Social Life," Annual Review of Anthropology, 59-88.

Beck, Ulrich (1992): The Risk Society: Towards a New Modernity. London: Sage.

Boykoff, Maxwell T. (2011): Who Speaks for the Climate: Making Sense of Media Reporting on Climate Change. Cambridge: Cambridge University Press.

Cochet, Yves (2015): “Green Eschatology," Clive Hamilton, François Gemenne, \& Christophe Bonneuil (eds.): The Anthropocene and the Global Environmental Crisis: Rethinking modernity. Abingdon: Routledge, 112-119.

Dagbladet (2005): "Enda mer ekstremt vær," 31 August, 2005, 2. [Editorial]

Daston, Lorraine \& Fernando Vidal (2004): "Doing What Comes Naturally," Daston, Lorraine \& Fernando Vidal (eds.): The Moral Authority of Nature. Chicago: The University of Chicago Press, 1-23.

Douglas, Mary \&Widavaky, Aaron (1983): Risk and Culture: An Essay on the Selection of Technological and Environmental Dangers. Berkeley, Ca: University of California Press.

Doyle, Julie (2011): Mediating Climate Change. Farnham: Ashgate.

Dunlap, Riley E. \& Aaron M. McCright (2010): "Climate Change Denial: Sources, Actors and Strategies," Lever-Tracy, Constance (ed.): Routledge Handbook of Climate Change and Society. Abingdon, UK: Routledge, 240-259.

Dunlap, Riley E. \& Aaron M. McCright (2011): "Organized Climate Change Denial," Dryzek, John S. Richard B. Norgaard \& David Schosberg (eds.). The Oxford Handbook of Climate Change and Society. Oxford: Oxford University Press.: https:// www.oxfordhandbooks.com/view/10.1093/oxfordhb/9780199566600.001.0001/ oxfordhb-9780199566600-e-10, (accessed 11/19/19).

Dynes, Russell \& Havidán Rodríguez (2007): "Finding and Framing Katrina: The Social Construction of Disaster," Brunsma, David.L., David Overfelt \& J. Steven Picou (eds.): The Sociology of Katrina: Perspectives on a Modern Catastrophe. 


\section{Culture Unbound}

Journal of Current Cultural Research

Lanham: Rowman \& Littlefield Publishers, 23-33.

Eklund, Trygve (2017): "Synlige klimadebattendringer," Aftenposten, 2 October, 2017, 17.

Ellestad Ole Henrik (2017): “Orkaner i USA - manipulert valgkampformidling," Reset, 4 October 4, 2017, October, 2017: https: //resett.no/2017/10/04/orkaner-i-usa-manipulert-valgkampformidling/, (accessed 03/08/19).

Eriksen, Anne, Ellen Krefting \& Anne Birgitte Rønning (2012): "Eksempelets makt," Eriksen, Anne, Ellen Krefting \& Anne Birgitte Rønning (eds.): Eksempelets makt: Kjønn, representasjon og autoritet fra antikken til i dag. Oslo: Scandinavian Academic Press, 9-38.

Field, Christopher B., Vicente Barros, Thomas F. Stocker, Dahe Qin, David Jon Dokken, Kristie L. Ebi, Michael D. Mastrandrea, Katharine J. Mach, Gian-Kasper Plattner, Simon K. Allen, Melinda Tignor \& Pauline M. Midgley (eds.) (2012): Managing the Risk of Extreme Events and Disasters to Advance Climate Change Adaption: Special Report of the Intergovernmental Panel on Climate Change [IPCC]. Cambridge: Cambridge University Press.

Fitzpatrick, Patrick J. (2006): Hurricanes: A Reference Handbook. Santa Barbara: ABC-Clio.

Frye, Northrop (1982): The Great Code: The Bible and Literature. New York: Harcourt Brace Jovanovich.

Gelbspan, Ross (2005): "Hurricane Katrina's real name," New York Times, 31 August, 2005: http: //www.nytimes.com/2005/08/30/opinion/30iht-edgelbspan.html? r=1, (accessed 01/25/19).

Gelley, Alexander (ed.) (1995): Unruly examples: On the rhetoric of exemplarity. Stanford: Stanford University Press.

Gilje, Nils \& Tarald Rasmussen (2002): Tankeliv i den lutherske stat: Norsk idéhistorie, vol. 2. Oslo: Aschehoug.

Halden arbeiderblad (1994): "Ikke storm da havariet fant sted," 29 September, 1994, 8.

Heidenblad, David Larsson (2012): Vårt eget fel: Moralisk kausalitet som tankefigur från 00-tallets klimalarm till förmoderna syndastraffsföreställningar. Höör: Agerings bokförlag.

Hertsgaard, Mark (2006): “Global Storm Warning”, Reed, Betsy (ed.): Unnatural Disaster: The Nation on Hurricane Katrina. New York: Nation Books, 17-21.

Holm, Isak Winkel (2012): "The Cultural Analysis of Disasters," Carsten Meiner \& Kristin Veel (eds.): The Cultural Life of Catastrophes and Crises. Berlin: de Gruyter, $15-32$.

Hulme, Mike (2008): "The conquering of climate: Discourses of fear and their dissolution," The Geographical Journal, 174:1, 5-16.

Hulme, Mike (2011): "Reducing the Future to Climate. A Story of Climate Determinism and Reductionism," Osiris, 26:1, 245-266.

Hulme, Mike (2017): Weathered: Cultures of Climate. London: Sage Publications.

Hörnfeldt, Helena (2018): "The End of the World: Apocalyptic Narratives in Children's Fears," Ethnologia Scandinavica, 48, 153-170.

Johns-Putra, Adeline (2016): “"My Job Is to Take Care of You': Climate Change, Humanity, and Cormac McCarthy's The Road," MFS Modern Fiction Studies 62:3, $519-540$.

Kermode, Frank (1967): The Sense of an Ending: Studies in the Theory of Fiction. New York: Oxford University Press.

Kluger, Jeffrey (2005): "Is Global Warming Fueling Katrina?," Times Magazine, 29 August, 2005: http: //www.time.com/time/nation/article/0,8599,1099102,00.html, (accessed 01/25/19).

Kverndokk, Kyrre (2015): Naturkatastrofer: En kulturhistorie. Oslo: Scandinavian Academic Press. 


\section{Culture Unbound}

Journal of Current Cultural Research

Kverndokk, Kyrre (2019): "The End of the World: From the Lisbon Earthquake to the Last Days," Jordheim, Helge \& Erling Sverdrup Sandmo (eds.): Conceptualizing the world: An Exploration across Disciplines. New York: Berghahn Books, 226-239.

Lakoff, George \& Mark Johnson (1980): Metaphors We Live By. Chicago: University of Chicago Press.

Lilly, Ingrid Esther (2016): “The Planet's Apocalypse: The Rhetoric of Climate Change," Kelly J. Murphy and Justin Jeffcoat Schedtler (eds.): Apocalypses in Context: Apocalyptic Currents through History. Minneapolis: Fortress, 359-379.

Lindahl, Carl (2012): "Legends of Hurricane Katrina: The Right to Be Wrong, Survivor-to-Survivor Storytelling, and Healing," Journal of American Folklore, 125: 496, 139-176.

Lyons, John D. (1989): Exemplum: The Rhetoric of Example in Early Modern France and Italy. Princeton: Princeton University Press.

Nasjonalbiblioteket [The National Library of Norway]. "NB N-gram Beta": https: $\quad / /$ www.nb.no/sp tjenester/beta/ngram 1/\#ngram/query?terms=ekstrem$\mathrm{v} \% \mathrm{C} 3 \%$ A6r\&lang $=$ all\&case sens $=0 \&$ freq $=$ rel\&corpus $=$ avis, , (accessed 01/24/19).

Nilsen, Yngve (2014): "Fra storm til ekstremvær: En 150 år lang historie," Tidsskrift for kulturforskning, 13:3, 22-35.

Nilsen, Yngve \& Magnus Vollset (2016): Vinden dreier: Meteorologiens historie $i$ Norge. Oslo: Scandinavian Academic press.

Norgaard, Kari Marie (2011): Living in Denial. Climate Change, Emotions, and Everyday Life. Cambridge, Ma: The MIT Press.

Northcott, Michael (2015): "Eschatology in the Anthropocene: From the chronos of deep time to the kairos of the age of humans," Clive Hamilton, François Gemenne \& Christophe Bonneuil (eds.): The Anthropocene and the Global Environmental Crisis: Rethinking modernity. Abingdon: Routledge, 100-111.

Mooney, Chris (2007): Storm World: Hurricanes, Politics, and the Battle over Global Warming. New York: Harcourt.

Ophir, Adi (2010): "The Politics of Catastrophization: Emergency and Exception," Didier Fassin \& Mariella Pandolfi (eds.): Contemporary States of Emergency: The Politics of Military and Humanitarian Interventions. New York: Zone Books, 59-88.

Ryghaug, Marianne (2006): “'Some like it hot': Konstruksjon av kunnskap om klimaendringer i norske aviser," Norsk medietidsskrift, 13:3, 197-219.

Rønning, Ole Chr. (2012): "Tidenes kraftigste orkan, kjære redaktør?," Telen, 11 November, 2012, 11 .

Sandberg, Tom (2012): "Lukker øynene for klimakatastrofen," Dagsavisen, 3 December, $2012,10$.

Schenk, Gerrit Jasper (2009): Katastrophen von Undergang Pompejis bis zum Klimawandel, Ostfildern: Thorbecke.

Schlosser, Kolson (2018): "Geohumanities and climate change skepticism," Geography Compass, 12:10: e12402.

Skrimshire, Stefan (2014): "Climate change and apocalyptic faith," WIREs Climate Change 2014:5, 233-246.

Smith, John E. (1969): “Time, Times, and the 'Right Time': 'Chronos' and 'Kairos',' The Monist, 53:11, 1-13.

Turner, Victor 1974. Dramas, Fields, and Metaphors: Symbolic Action in Human Society. Ithaca, NY: Cornell University

Vassnes, Bjørn (2005): "Vi bor alle i New Orleans," Klassekampen, 7 September, 2005,9 . 